\title{
Experimental Analysis of the Seakeeping Performance of Catamaran Forms with Bulbous Bows
}

\author{
Pauzi ABDUL GHANI ${ }^{\text {a }}$, Philip WILSON b,1 \\ ${ }^{\text {a Universiti Teknologi Malaysia }}$ \\ ${ }^{\mathrm{b}}$ University of Southampton, $U K$
}

\begin{abstract}
.
This paper explores the effects of adding different forms of bulbous bows onto catamaran hulls and assesses the implications on the seakeeping performance. There has been a large body of work that assess the effect of wave wake wash and recently studies have been undertaken to determine the effects of bulbous bows on reducing wave wake wash. However, not much research has been published on the effects of bulbous bows on the seakeeping performance of catamarans fitted with bulbous bows. This paper presents experimental results that will allow a ship designer to understand the effects of bulbous bows on heave, pitch and added resistance in waves. In conclusion it ranks the importance of different bulbous bows on the seakeeping performance.
\end{abstract}

Keywords. Bulbous bow,seakeeping, added resistance, heave, pitch, waves

\section{Background}

In recent years fast ferries which are capable of speeds in excess of 40 knots have been operational in water of depth of less than $10 \mathrm{~m}$. As high-speed operations near sensitive shorelines increase, complaints from the public on extensive wave wake or wake wash from these fast vessels have increased. Although the leading waves in the wash are very small in terms of wave amplitude compared to storm waves, they have a very long period and build in height rapidly in shallow water at the shoreline, thereby, causing substantial surges on beaches as well as breaching sea walls at high tide. This wake wash is likely to have environmental effects such as shoreline erosion as well as endangering swimmers and small boats. During 1997, as a consequence of public concern, the Danish Maritime Authority issued a governmental order which requires that the high-speed craft operator/owner has to show evidence that the ship-generated waves do not exceed a prescribed wave height criterion in shallow water along the entire route. Similar criteria exist for other regions, such as the Puget Sound, Seattle, some navigable inland waterways in the Netherlands and the River Thames, UK [2], [3], [4],[5], [6]. There are other areas which are equally sensitive to damage such as the Paramatta River in Australia, the Solent (i.e.

\footnotetext{
${ }^{1}$ Corresponding Author: Faculty of Engineering and the Environment, University of Southampton, U.K.; E-mail: philip.wilson@soton.ac.uk.
} 
particularly the route between Southampton and the Isle of Wight), Nantucket, the Mare Island Channel and the East Bay Estuary in San Francisco Bay. The main risk to coastal communities and users of the waters in coastal areas is that the waves arrive unexpectedly and break on the shoreline often after the fast ferry is out of sight, Whittaker (2001) [7]. Shallow water dramatically increases the wash. In shallow waters, the seabed interfere with ship wave-making forcing changes to wave patterns, energy levels and vessel running condition.

\section{Introduction}

In recent papers [1], [20] the authors published the results of the resistance experiments undertaken by the authors were presented; in this new paper the work is extended to include the include the seakeeping analysis of the same set of hulls.

High speed displacement ships are characterized by their high length-beam ratio, sharp bow, and flat stern terminating in a transom. This type of hull is often used for small warships, patrol boats or as fast ferries particularly in a catamaran configuration which combines high-speed capability with good seakeeping characteristics.

Important issues in the design of ships are safety, reliability and economy. To some extent all of these aspects are affected by seakeeping characteristics of the ship. To improve seakeeping or ship seaworthiness is one of the most demanding tasks in the design of high speed craft. Seaworthiness is the performance quality of the ship which allows the accomplishment of her missions under specified sea conditions with acceptable passenger or personnel comfort; minimal deck wetness, motions and hull-wave impact; and also assurance of hull structural integrity.

The resistance or drag of a vessel travelling at constant speed in waves will oscillate at the frequency of the encountered waves. But the average drag in waves will be greater than the drag in calm water. This extra drag which a vessel experiences in a seaway, compared to with in calm water, is known as added resistance, $R_{A W}$. This paper will address the effect of added resistance.

Wake wash often known as wash, results from ship-generated waves. There is a general awareness of the importance of ship-generated waves in design. However, until recently, ship-generated waves analysis has not been fully considered in design studies except as one of ship's resistance component resulting from the energy expended in generating a wave pattern. As the design spiral is the traditionally accepted way of representing the ship design process, wash was not considered to play a part. The main dimensions and form are clearly fixed by other considerations. One may think of wash as another spoke of the wheel because the elements of design which affect wash are also directly related to ship performance such as resistance, stability, seakeeping, deadweight capacity.

\section{Bulb Effects}

Although the study of ship-generated waves has been carried out from the middle of the nineteenth century, emphasis has been placed on the determination of a ship's resistance resulting from the energy expended in generating a wave pattern. It has been accepted 
and recognized that the use of a bulbous bow can reduce a ship's wave-making resistance. A quantitative relationship between the character of the waves generated by a ship, as a function of the ship type, size, draught, speed, water depth etc is often desirable in the investigation of wake wash. In this study, the effects of bulbous bow on the sea keeping performance are explored.

The aim of this work is to find the best combination of the existing hullform of the high-speed displacement catamaran (NPL5b), see Insel (1992) [8] and bulbous bow/bulb type that have considerably less motion without compromising other attributes such as resistance \& propulsion of the vessel. The approach of this study is to incorporate different bulbous bows into the existing NPL5b series catamaran hull form.

\section{Bulbous bow design}

\subsection{Background}

Bulbous bows are used on almost all modern ocean-going ships. They actually create their own wave system, which cancels the hull's bow wave. A properly designed bulbous bow can certainly improve the running efficiency of a hull and reduce vertical accelerations as well. A number of new designs incorporate a bulbous bow and some yachts utilize a retrofitted bulbous bow to improve their performance at sea.

A bulbous bow was discovered rather than invented. Model testing studies in the United States with warships established that the ram stem projecting below the water had a resistance decreasing effect. A torpedo boat model showed that an underwater torpedo discharge tube ending in the forward stem also reduced the resistance. D.W Taylor was the pioneer when it was recognized that the bulbous bow reduces the wave making resistance, Schneekluth (1992).[9]

General rules concerning the position and size of bulbous bows and the speeds at which it will be useful have been drawn up by Wigley (1936) [10] all based upon the optimisation of ship resistance i.e.

1. The useful speed range is generally from $F_{n}=0.24$ to 0.57 .

2. The top of the bulb should not be too close to the water surface; and as a working rule it is suggested that the immersion of the highest part of the bulb should be equal or greater than its own total diameter.

\subsection{Notes on bulbous bows}

For slender hull forms such as a NPL5b catamaran, the primary reduction in resistance is due to the reduction of the free wave system of the ship. This reduction of the free wave system is accomplished by cancellation, which depends on the phase and amplitudes of the waves created by the bulb and the ship, the two may cancel totally. The phase difference of the two wave systems is determined by the location of the bulb, and the amplitude of the bulb's wave is determined by bulb volume. However, very little information is known or published on the effects on seakeeping.

To re-iterate the design that is given in the paper by the authors [1]. Generally this type of bulb or bulbous bow can be broadly classified into three main types as shown in Figure 1. 


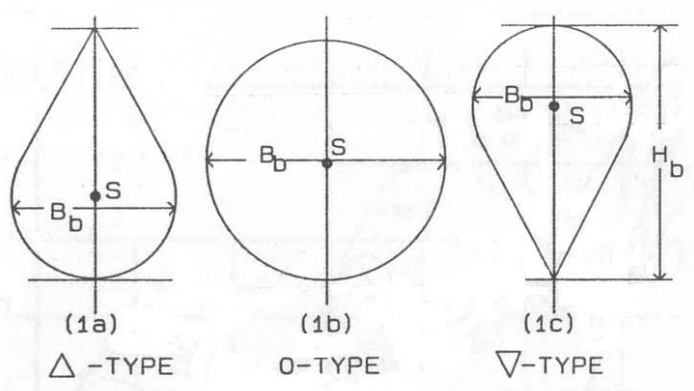

Figure 1. Types of bulbous bow

- Delta Type

This delta type indicates a concentration of the bulb volume toward the baseline with the drop-shaped cross sectional area, $A_{B T}$. The Taylor bulb and pear-shape bulb belong to this group. However, this type of bulbous bow is no longer built today due to their unfavourable perceived seakeeping properties.

- Nabla Type

This group of bulbous bow also has a drop-shaped cross sectional area $A_{B T}$ but with its centre of area in the upper-half near to the free surface. All modern bulbous bows belong to this group because of its perceived favourable seakeeping properties.

- O Type

This O-Type has an oval sectional area $A_{B T}$ and central volumetric concentration. All circular, elliptical and cylindrical shaped bulbs belong to this group.

They also could be defined by the following form characteristics:

1. Shape of section

2. Length of projection beyond perpendicular

3. Area ratio

The bulbous bow cross section $A_{B T}$ influences the size of the wave generated, while its length $L_{P R}$ determines the phase of the bulbous bow generated waves and also its volume is related to the amplitude. One important parameter is depth below the surface. If the bulbous bow submergence is too deep it will not be of much benefit in reducing wave resistance, but if it is too shallow it may breach the surface at higher speeds. The forward end of the bulbous bow can be spherical or an elliptical shape.

The cross section can be cylindrical or others as mentioned in previous section or of varying cross section along its length. The shape or cross section is usually determined by seakeeping consideration and other factors such as resistance as well as production kindliness. 


\subsection{Bulbous bow for NPL5b series hull form}

Bulbous bows with circular cross section are preferred for further investigation in relation to wave wash because of their simple design. Schneekluth (1987) [9], in his studies on this type of bulbous bow, he showed that the potential danger of slamming effects can be avoided. This type of bulbous bow was also recommended by Kracht (1978) [11] for the slender hull form. It fits well with $U$ and $V$ types of forebody sections and offers space for sonar equipment if required.

The diameter of the bulbous bow was chosen based on several design parameters as suggested by Kracht (1978) [11], Wehausen (1973) [12], Tuck (1991) [21] and Roddan (1999) [13]. The summary of those results are shown in Table 1. Consideration of those parameters, meant that the $48 \mathrm{~mm}$ diameter has been chosen for this particular model for further investigation.

\begin{tabular}{|l||c|l|}
\hline Design Parameter & Approx. $D_{\text {bulb }}$ & Remarks \\
\hline \hline Roddan [13] & $58 \mathrm{~mm}$ to $63 \mathrm{~mm}$ & based on draught and clearance to MSL \\
\hline Tuck [21] & $48 \mathrm{~mm}$ & based on draught and clearance to MSL \\
\hline Kracht's $C_{Z B}[11]$ & $42 \mathrm{~mm}$ & depth parameter \\
\hline Kracht's $C_{L P R} \& C_{\nabla P R}$ & $26 \mathrm{~mm}$ & length parameter, too small \\
\hline Kracht's $C_{A B T}$ & $31 \mathrm{~mm}$ & cross-section parameter \\
\hline
\end{tabular}

Table 1. Summary of bulb diameter

Although, the projecting length $L_{P R}$ is varied but it is not allowed to project longitudinally beyond the upper end of the stem for safety reasons, with consideration for operations such as anchor handling, docking and manoeuvring.

Four different bulbous bows have been developed by varying the bulbous bow's projecting length $L_{P R}$ between $20 \mathrm{~mm}$ and $100 \mathrm{~mm}$. These bulbous bows have been designed and faired to the parent hull, whilst the afterbody and the forebody from amidship to $0.3 L_{p p}$ is kept unchanged. These shapes are illustrated in Figure 2

The cross section parameter, $C_{A B T}$ has been fixed at value 0.131 i.e. the ratio of bulbous bow cross section area at FP to the midships section area. Other bulbous bow details are shown in Table 2.

\begin{tabular}{|l||c|c|c|c|c|c|}
\hline Bulb No. & $C_{L P R}$ & $C_{B B}$ & $C_{Z B}$ & $C_{A B L}$ & $C_{A B T}$ & $C_{\nabla P R}$ \\
\hline \hline Bulb01 & 0.013 & 0.331 & 0.329 & 0.119 & 0.303 & 0.0032 \\
\hline Bulb02 & 0.028 & 0.331 & 0.329 & 0.320 & 0.303 & 0.0098 \\
\hline Bulb03 & 0.044 & 0.331 & 0.329 & 0.521 & 0.303 & 0.0163 \\
\hline Bulb04 & 0.063 & 0.331 & 0.329 & 0.763 & 0.303 & 0.0241 \\
\hline
\end{tabular}

Table 2. Bulbous Bow Parameters for NPL5b Hull

\section{Model tests}

The seakeeping experiments were conducted in three different establishments namely the University of Southampton Lamont Tank, the Southampton Solent University tank for 


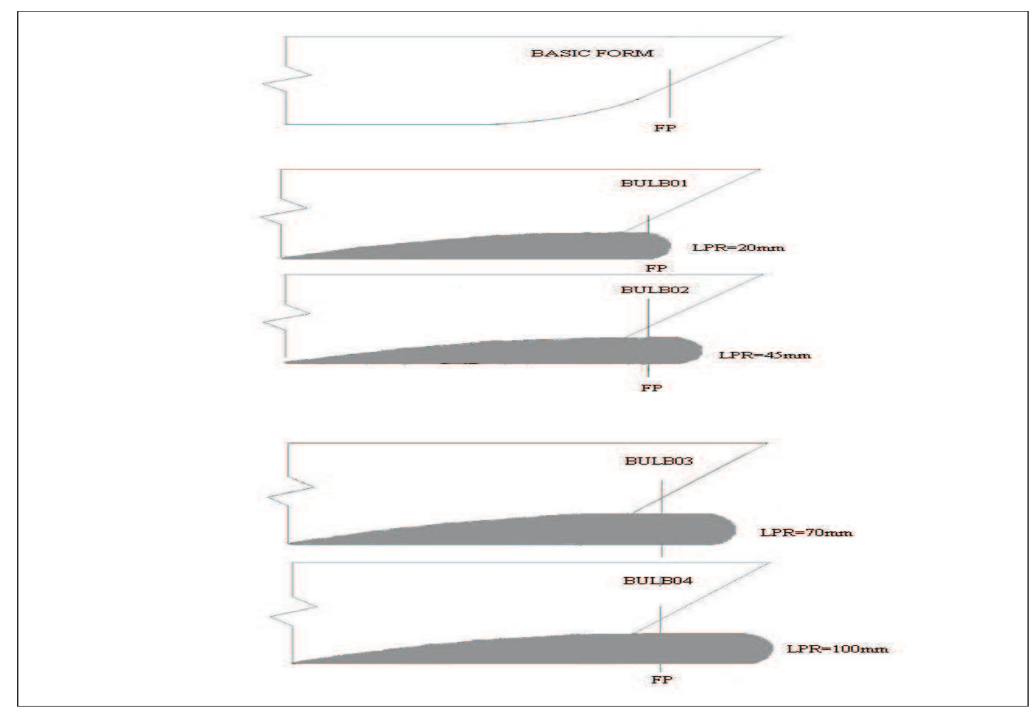

Figure 2. Profile of Bulbous Bows

deep water condition whereas the GKN Westland Aerospace Ltd.'s tank, Isle of Wight was used for the shallow water condition. (n.b. The GKN is no longer operational) The details of these tanks are given in Table 3.

\begin{tabular}{|ll|}
\hline Length & $30.0 \mathrm{~m}$ \\
Breadth & $2.40 \mathrm{~m}$ \\
Depth & $1.20 \mathrm{~m}$ \\
Max. Carriage Speed & $3.0 \mathrm{~m} / \mathrm{s}$ \\
\hline \multicolumn{2}{|c|}{ A. Lamont Tank Details } \\
\hline
\end{tabular}

\begin{tabular}{|lr|}
\hline Length & $60.0 \mathrm{~m}$ \\
Breadth & $3.70 \mathrm{~m}$ \\
Depth & $1.80 \mathrm{~m}$ \\
Max. Carriage Speed & $4.2 \mathrm{~m} / \mathrm{s}$ \\
\hline \multicolumn{2}{|c|}{ B. SIHE Tank Details } \\
\hline
\end{tabular}

\begin{tabular}{|lc|}
\hline Length & $200.0 \mathrm{~m}$ \\
Breadth & $4.60 \mathrm{~m}$ \\
Depth & $0.40 \mathrm{~m}$ \\
Max. Carriage Speed & $14.0 \mathrm{~m} / \mathrm{s}$ \\
\hline
\end{tabular}

C. GKN Westland Tank Details

Table 3. Towing Tanks Details

The raison d'etre of this study was to investigate the behaviour and performance of the four bulbous bows in shallow waters in a range of speeds covering the sub-critical, critical and super-critical speeds.

Concerning the critical speed, there are at least three different speeds in shallow water that are close to critical as illustrated by Hofman (1998) [14];

- It is the maximum speed of the transverse waves in water depth $h, v=\sqrt{g h}$, critical. 
- Also, it is the speed corresponding to the peak value of wave-making resistance curve.

- Also, the critical speed is sometimes called the speed corresponding to the maximum of shallow water resistance ratio, i.e. the ratio between shallow water resistance and deep water resistance.

\subsection{Description of the catamaran models}

Figure 3 illustrates the removable part of the bulbous bow and other details. Details of the ship models used in the investigation are given in, Table 4.

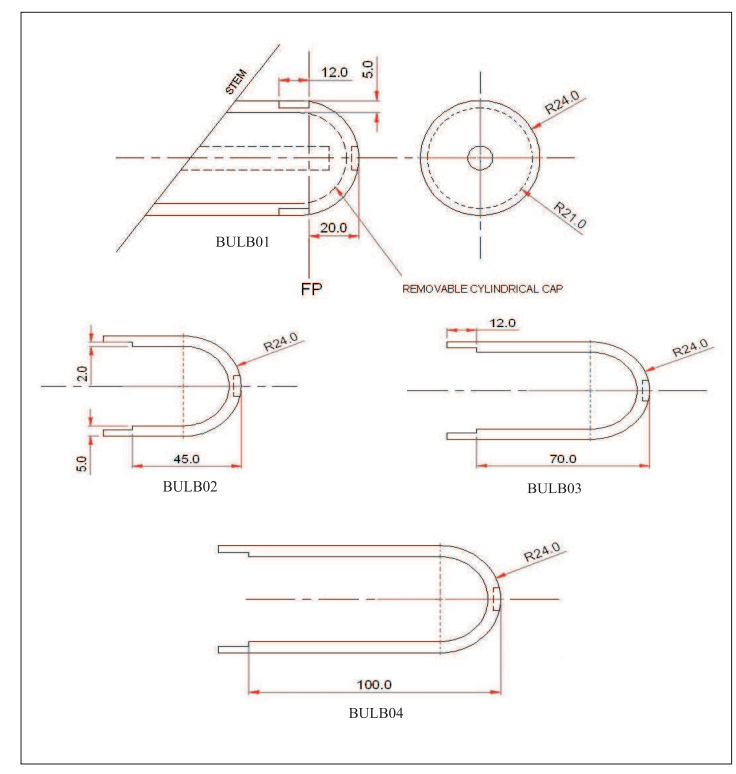

Figure 3. Bulbous Bow's Details

The model was towed horizontally at the longitudinal centre of gravity and at an effective height of one third of the draught above the keel. The models were fitted with turbulence stimulation studs of $3.2 \mathrm{~mm}$ diameter and $2.5 \mathrm{~mm}$ height at a spacing of $25 \mathrm{~mm}$. Those studs were situated $37.5 \mathrm{~mm}$ aft of the stem. No underwater appendages were attached to the models.

All tests were carried out in calm water for wash tests and in regular waves for seakeeping tests over a wide range of speeds corresponding to the length Froude number 0.3 to 0.6 and 0.26 to 1.02 for Lamont tank, University of Southampton and Southampton Solent University tank respectively. The corresponding Reynolds number $R_{n}$ for the models within those speed range was between $1.85 \times 10^{6}$ and $3.54 \times 10^{6}$. Before testing began, all bulbs were appended to a $1.6 \mathrm{~m}$ NPL5b series catamaran fitted with a removable bow section. Each model configuration was ballasted to a designed waterline, $0.0725 m$ at level trim. These are reported in Abdul Ghani (2003) [15]. 


\begin{tabular}{|l||l|l|l|l|l|}
\hline Item & $N P L$ & $N P L_{\text {bulb01 }}$ & $N P L_{\text {bulb02 }}$ & $N P L_{\text {bulb03 }}$ & $N P L_{\text {bulb04 }}$ \\
\hline \hline$L, m$ & 1.6 & 1.6 & 1.6 & 1.6 & 1.6 \\
\hline$B, m$ & 0.145 & 0.145 & 0.145 & 0.145 & 0.145 \\
\hline$T, m$ & 0.073 & 0.073 & 0.073 & 0.073 & 0.073 \\
\hline$\nabla, m^{3}$ & 0.006461 & 0.006771 & 0.006817 & 0.006862 & 0.006917 \\
\hline$W S A, m^{2}$ & 0.267 & 0.315 & 0.319 & 0.323 & 0.327 \\
\hline$L C B, \mathrm{~m}$ & -0.065 & -0.062 & -0.056 & -0.050 & -0.043 \\
\hline$L / B$ & 11.0 & 11.0 & 11.0 & 11.0 & 11.0 \\
\hline$B / T$ & 2.0 & 2.0 & 2.0 & 2.0 & 2.0 \\
\hline$L / \nabla^{\frac{1}{3}}$ & 8.591 & 8.457 & 8.438 & 8.420 & 8.397 \\
\hline$C_{B}$ & 0.380 & 0.400 & 0.403 & 0.405 & 0.408 \\
\hline$C_{P}$ & 0.676 & 0.709 & 0.715 & 0.718 & 0.723 \\
\hline$C_{M}$ & 0.564 & 0.564 & 0.564 & 0.564 & 0.564 \\
\hline$C_{W}$ & 0.736 & 0.736 & 0.736 & 0.736 & 0.736 \\
\hline
\end{tabular}

Table 4. Models Particulars

\section{Experiments in regular waves}

A ship sailing in a seaway experiences the largest added resistance in waves from ahead. For that reason the study has been confined to that important wave heading; head seas. Also due to the limitations of the tank test facility at Southampton Solent University, only head sea conditions were considered and to simplify the programme the models were towed rather than self-propelled.

Experiments in waves have been carried out on the model fitted with four different bulbs (bulb01, bulb02, bulb03 and bulb04) to compare the pitching and the heaving motions as well as the added resistance, details of conditions tested are in Table 5.

\begin{tabular}{|c|l||c|c|c|c|}
\hline $\mathrm{V} \mathrm{m} / \mathrm{s}$ & $F_{n l}$ & Bulb01 & Bulb02 & Bulb03 & Bulb04 \\
\hline \hline 1.028 & 0.26 & $\sqrt{ }$ & $\sqrt{ }$ & $\sqrt{ }$ & $\sqrt{ }$ \\
1.226 & 0.31 & $\sqrt{ }$ & $\sqrt{ }$ & $\sqrt{ }$ & $\sqrt{ }$ \\
1.613 & 0.41 & $\sqrt{ }$ & $\sqrt{ }$ & $\sqrt{ }$ & $\sqrt{ }$ \\
2.019 & 0.51 & $\sqrt{ }$ & $\sqrt{ }$ & $\sqrt{ }$ & $\sqrt{ }$ \\
2.448 & 0.62 & $\sqrt{ }$ & $\sqrt{ }$ & $\sqrt{ }$ & $\sqrt{ }$ \\
2.817 & 0.71 & $\sqrt{ }$ & $\sqrt{ }$ & $\sqrt{ }$ & $\sqrt{ }$ \\
3.368 & 0.85 & $\sqrt{ }$ & $\sqrt{ }$ & $\sqrt{ }$ & $\sqrt{ }$ \\
4.042 & 1.02 & $\sqrt{ }$ & $\sqrt{ }$ & $\sqrt{ }$ & $\sqrt{ }$ \\
\hline
\end{tabular}

Table 5. The test matrix for experiment in regular waves $\lambda / L=0.5-2.0$

\subsection{Tank Facilities}

The tank is fitted with flap type wave makers at the one end, capable of generating both regular and irregular waves of various heights and frequencies and also fitted with a beach or wave absorber at the other end. The dimensions of the tank are given in the previous section. 
The tank is equipped with a manned carriage and is rigged with a microcomputer based data acquisition system, a two component dynamometer and a heavy model dynamometer. Acceleration distance in the tank is about $20 \mathrm{~m}$ which was sufficient to achieve the maximum speed used in the experiment, i.e. $4.04 \mathrm{~m} / \mathrm{s}$. A section of $15.24 \mathrm{~m}$ long was used during the measurement.

\subsection{Instrumentation and measurements}

The total model resistance and side force measurements were performed using the Wolfson Unit dynamometer. Total resistance and side force were recorded for all the speeds tested. Side force was monitored at all speeds to ensure that the model yaw degree was acceptable. The accuracy of the total resistance was found to be in the range of $\pm 0.02 N$.

Heave motions were measured with a linear potentiometer attached to the heave post. The accuracy of the linear potentiometer was found to be $\pm 0.1 \mathrm{~mm}$. Pitch was measured with an angular potentiometer incorporated into the towing fitting. It was measured as angle in degrees and taken positive for bow up. The accuracy of the potentiometers was in the range of $\pm 0.05^{\circ}$.

The speed of the model is determined by measuring the time taken by the carriage to cover the constant run length between two switches which are $15 \mathrm{~m}$ apart. The switches also start and stop the data acquisition process.

\subsection{Model details}

The model used in this work is a catamaran, $s / L=0.2$ which is fitted with four different bulbous bows. The $s / L=0.2$ value chosen, corresponding to a demihull separation of $0.32 \mathrm{~m}$, as this is representative of the vast majority of similar high speed catamarans around at the current time as reported by Couser (1996) [16]. The models were accordingly ballasted and trimmed. During testing, the models were free to heave and pitch but restrained in yaw, sway and roll.

\subsection{Test conditions}

The experiments were performed in the Southampton Solent University towing tank in head sea conditions. For the present test programme, regular waves were used covering a wavelength to ship length ratio $\lambda / L$ range of between 0.5 and 2.0 whilst the wave height was maintained at $0.030 \mathrm{~m}$. The experiments were carried out for eight ship speeds, corresponding to Froude number range between 0.26 and 1.02 . The steady speed run length was $15 \mathrm{~m}$. The wave frequency were set for each Froude number so that it gave a constant encounter frequency range. The details of regular waves used are shown in Table 6.

During regular wave tests the models were allowed to encounter at least 5 to 6 waves before the responses were recorded, so as to allow transients in the response to die out. The experiments were confined to the design draught only.

\subsection{Tests in Waves}

Tests on catamaran $s / L=0.2$ in regular waves have been carried out. It should be noted that the $s / L=0.2$ value chosen is representative of the vast majority of similar highspeed catamarans around at the current time. 


\begin{tabular}{|c||c|c|c|c|}
\hline$\lambda / L$ & $\lambda m$ & Tsec & $\omega \mathrm{rad} / \mathrm{s}$ & $\omega \sqrt{\frac{L}{g}}$ \\
\hline \hline 0.50 & 0.80 & 0.716 & 8.778 & 3.545 \\
0.75 & 1.20 & 0.877 & 7.167 & 2.894 \\
1.00 & 1.60 & 1.012 & 6.207 & 2.507 \\
1.25 & 2.00 & 1.132 & 5.551 & 2.242 \\
1.50 & 2.40 & 1.240 & 5.068 & 2.047 \\
2.00 & 3.20 & 1.432 & 4.389 & 1.772 \\
\hline
\end{tabular}

Table 6. Regular waves details used in seakeeping experiment

The added resistance in waves varies with speed and the wavelength to ship length ratio $\lambda / L$ and the model fitted with bulb02 offers the lowest value. It should be noted that the vessel having least resistance in calm water does not necessarily show the lowest added resistance in seaway or rough water.

It was found that the wash measured in calm water is the similar trends as the wash measured in regular waves, but with small phase shift and oscillations in some places. From this preliminary finding, it may be concluded that the wash tends to be independent of sea condition.

From the results of the experiment in regular head waves, it was found that the pitch motion was influenced by the size of the bulbous bows i.e. in this particular case, bulb03 and bulb04 are preferable for a least pitch motion.

The effect of bulbous bow size on heave motion is less pronounced. However, in heave motion the wavelength and Froude number have a much greater effect than the size of bulbous bow.

\subsection{Shallow Water Tests}

The results of a series of a model experiments for high-speed catamarans in shallow water were discussed in [1], and [20]. The study concentrated on resistance, wash cuts, sinkage and trim.

It can be seen that the general effect of the shallow water is to cause an increase in resistance especially at the lower speeds compared with the deep-water value.

By referring to the total and residuary resistance coefficients in shallow water, the shortest bulbous bow i.e. bulb01 is superior and preferable among the four bulbous bows.

In comparison with deep water results, it was found that the wash in shallow water increases by $40 \%$ to $100 \%$ which depends on $F_{n h}$ and bulbous bows (bulbo1, bulb02, bulb03 or bulb04). Again, the shortest bulbous bow i.e. bulb01 performs better than others in producing a low wash.

As expected, the trim varies with the size of the bulbous bows. The longest bulbous bow i.e. bulb04 increases trim by $30.0 \%$ with reference to bulb01.

The experimental results also show that the sinkage experienced by the model fitted with bulb02 and bulb04 increased by $46.6 \%$ and $27.5 \%$ respectively with respect to bulb01 but in contrast bulb03 offered a $0.5 \%$ reduction. 


\section{Experimental Results}

The experimental results are shown in the following figures 4, 5, 6,7, where the dimensionless heave and pitch amplitudes and the added resistance are plotted on a base of the ratio waterline and wave length and encounter frequency.
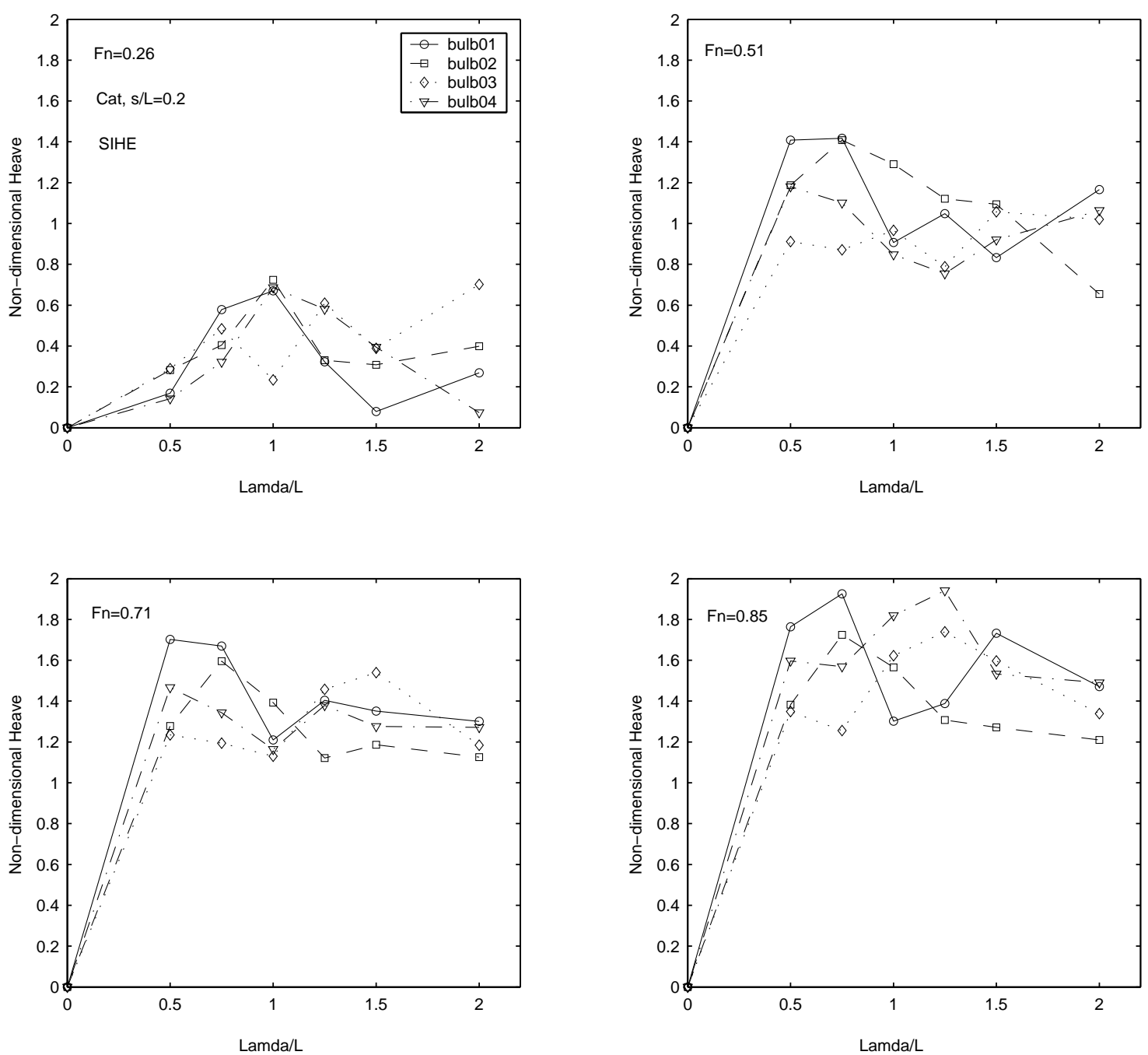

Figure 4. Response functions of heave of catamaran $s / L=0.2$ with different bulbous bows

\subsubsection{Added Resistance in Regular Waves}

The added resistance in regular wave is the difference between the calm water resistance and the resistance in the waves at the same speed. The non-dimensional added resistance is expressed as; 

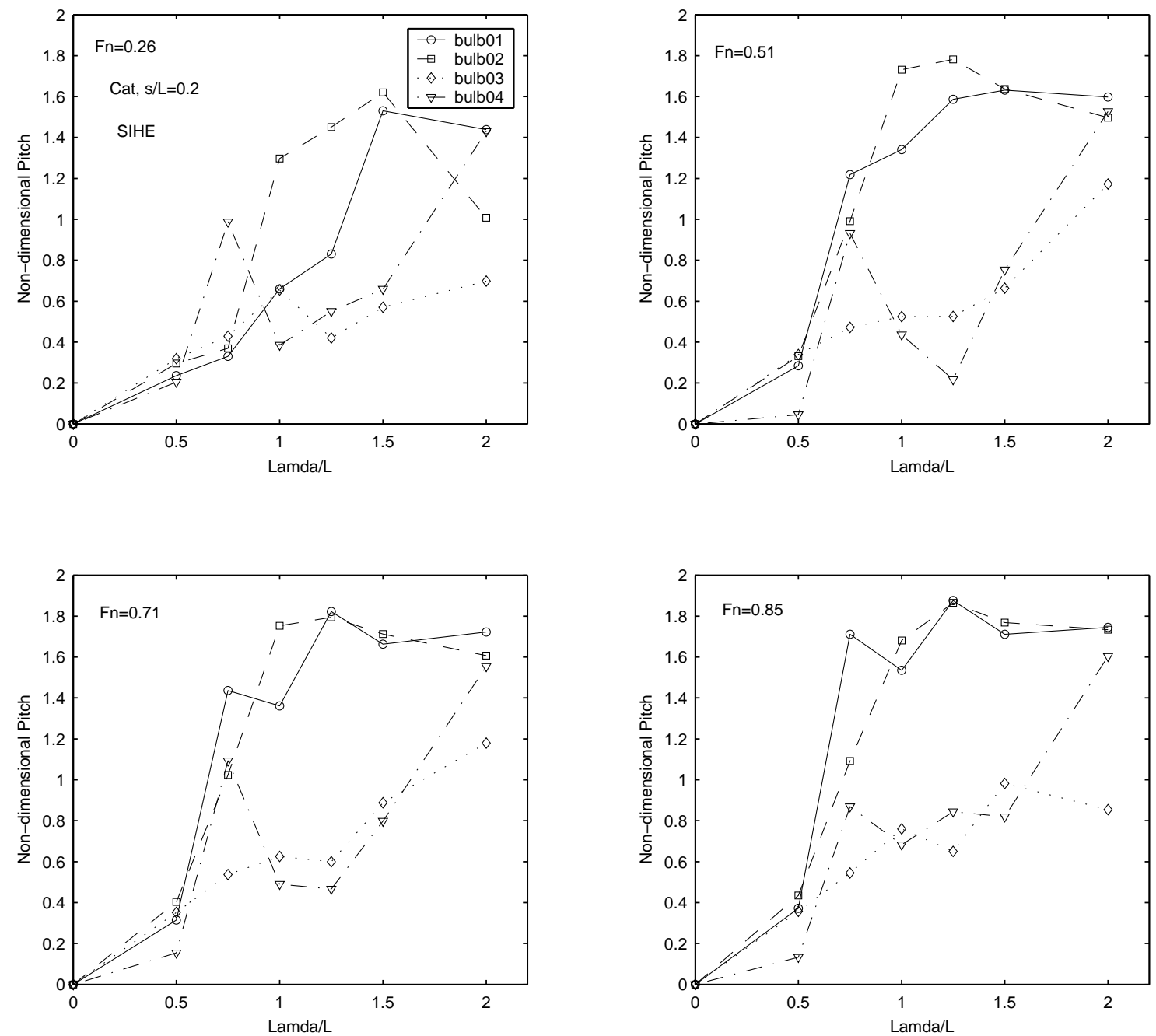

Figure 5. Response functions of pitch of catamaran $\mathrm{s} / \mathrm{L}=0.2$ with different bulbous bows 

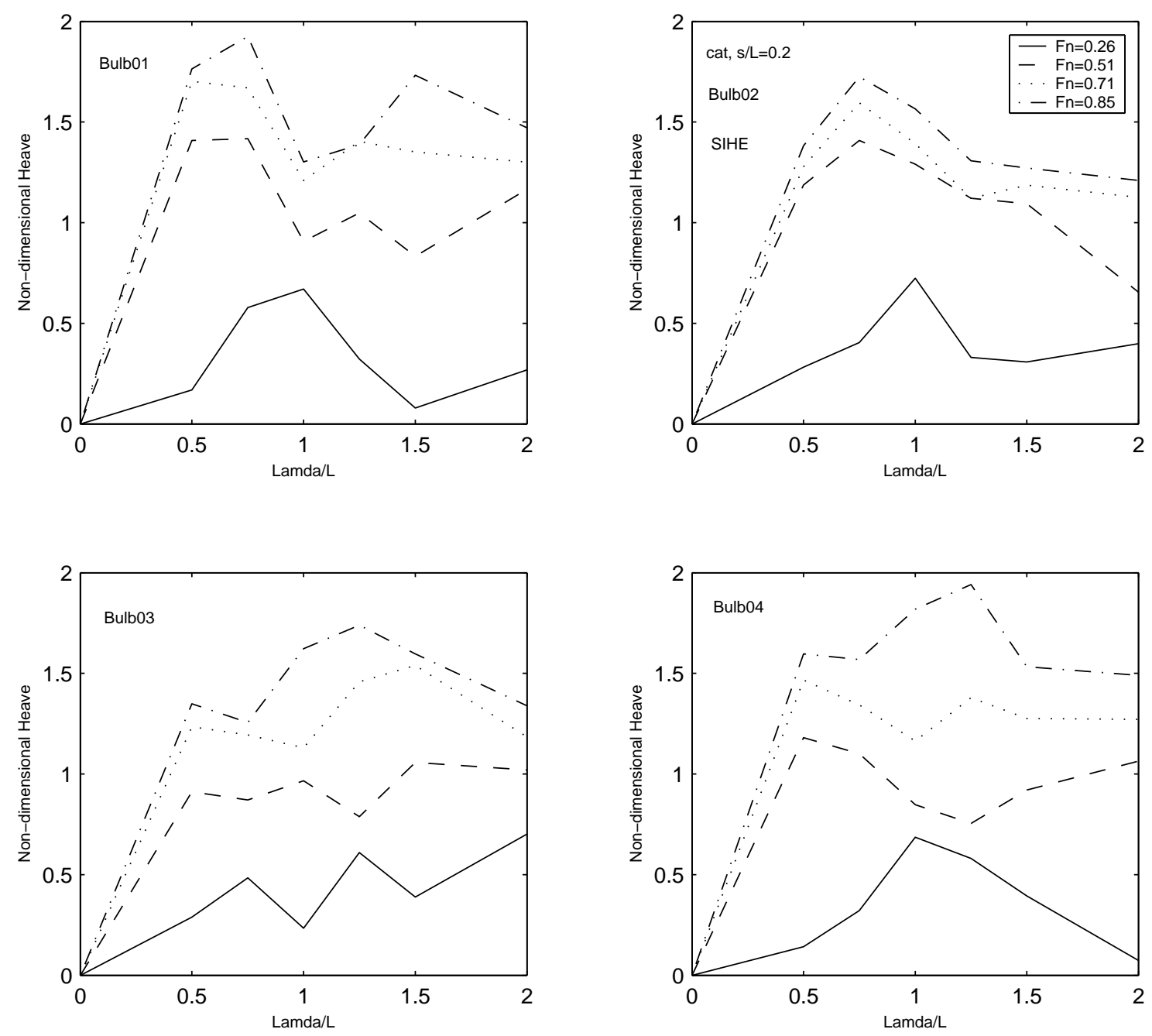

Figure 6. Response functions of heave of catamaran $\mathrm{s} / \mathrm{L}=0.2$ with different bulbous bows 

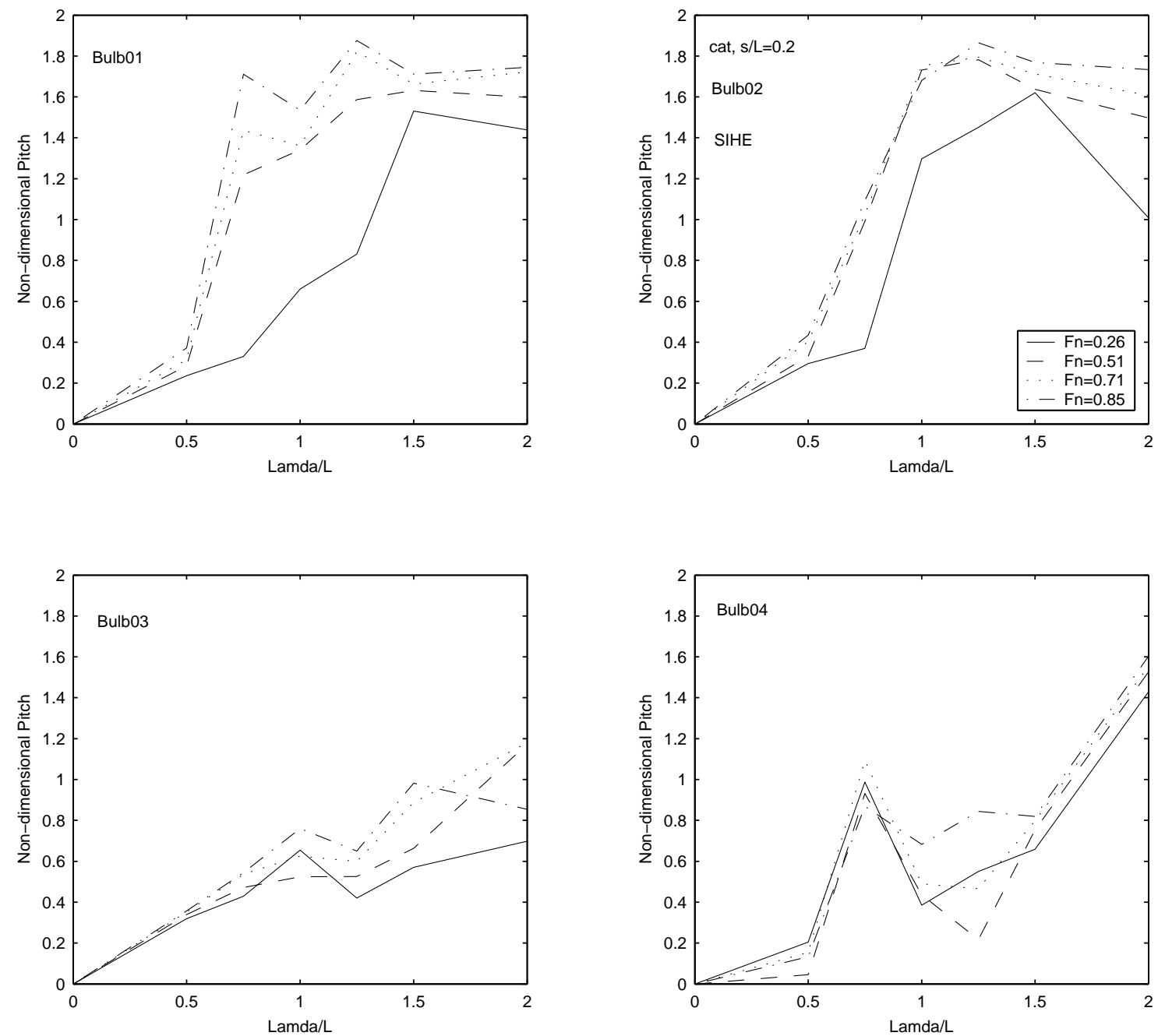

Figure 7. Response functions of pitch of catamaran $\mathrm{s} / \mathrm{L}=0.2$ with different bulbous bows 


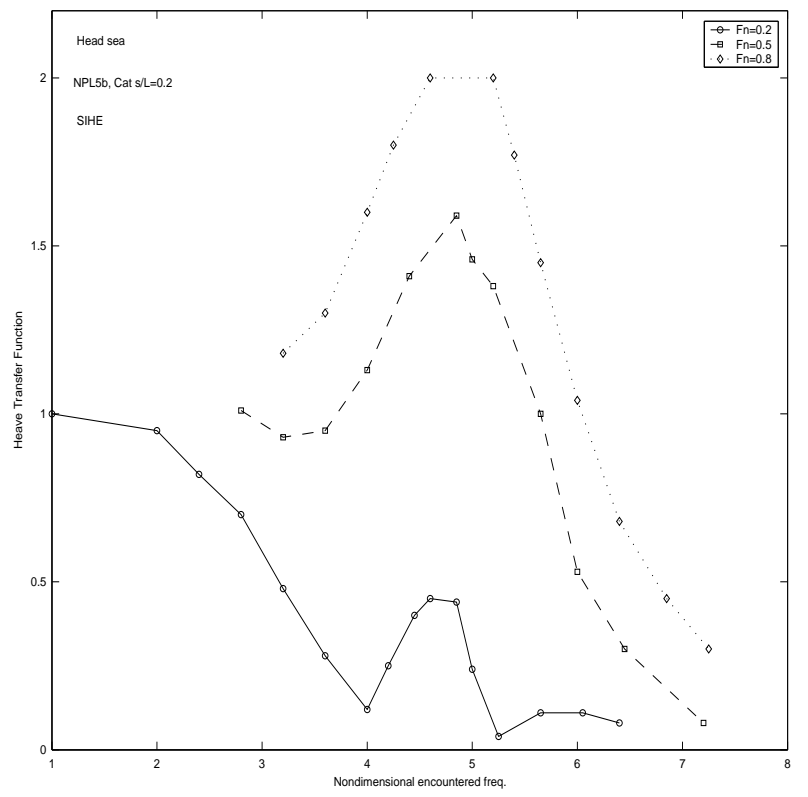

Figure 8. Response Functions of Heave for Model NPL5b Catamaran s/L=0.2 in Head Seas[19]

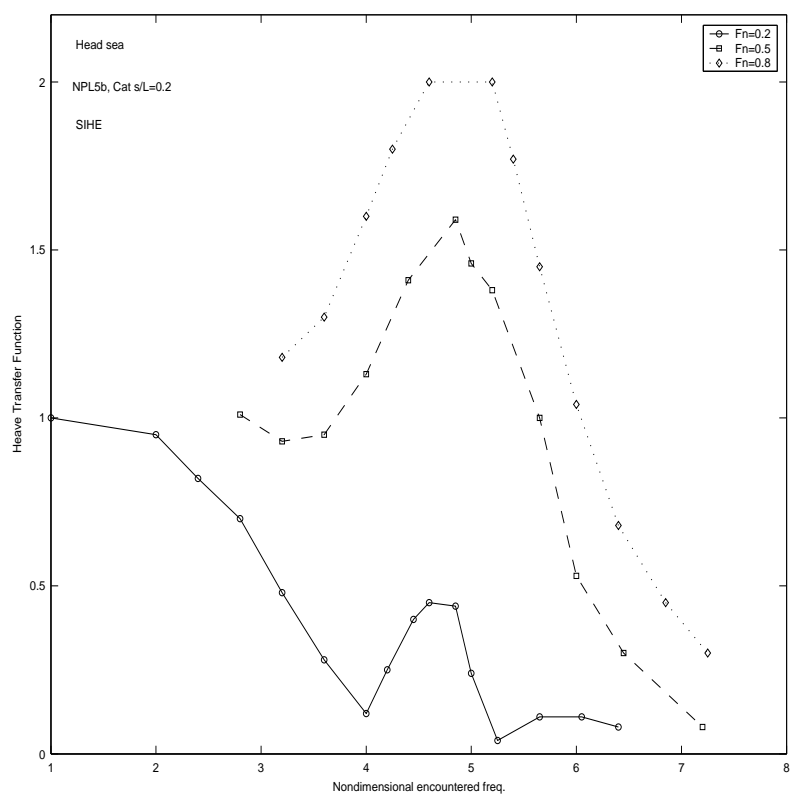

Figure 9. Response Functions of Pitch for Model NPL5b Catamaran s/L=0.2 in Head Seas[19] 

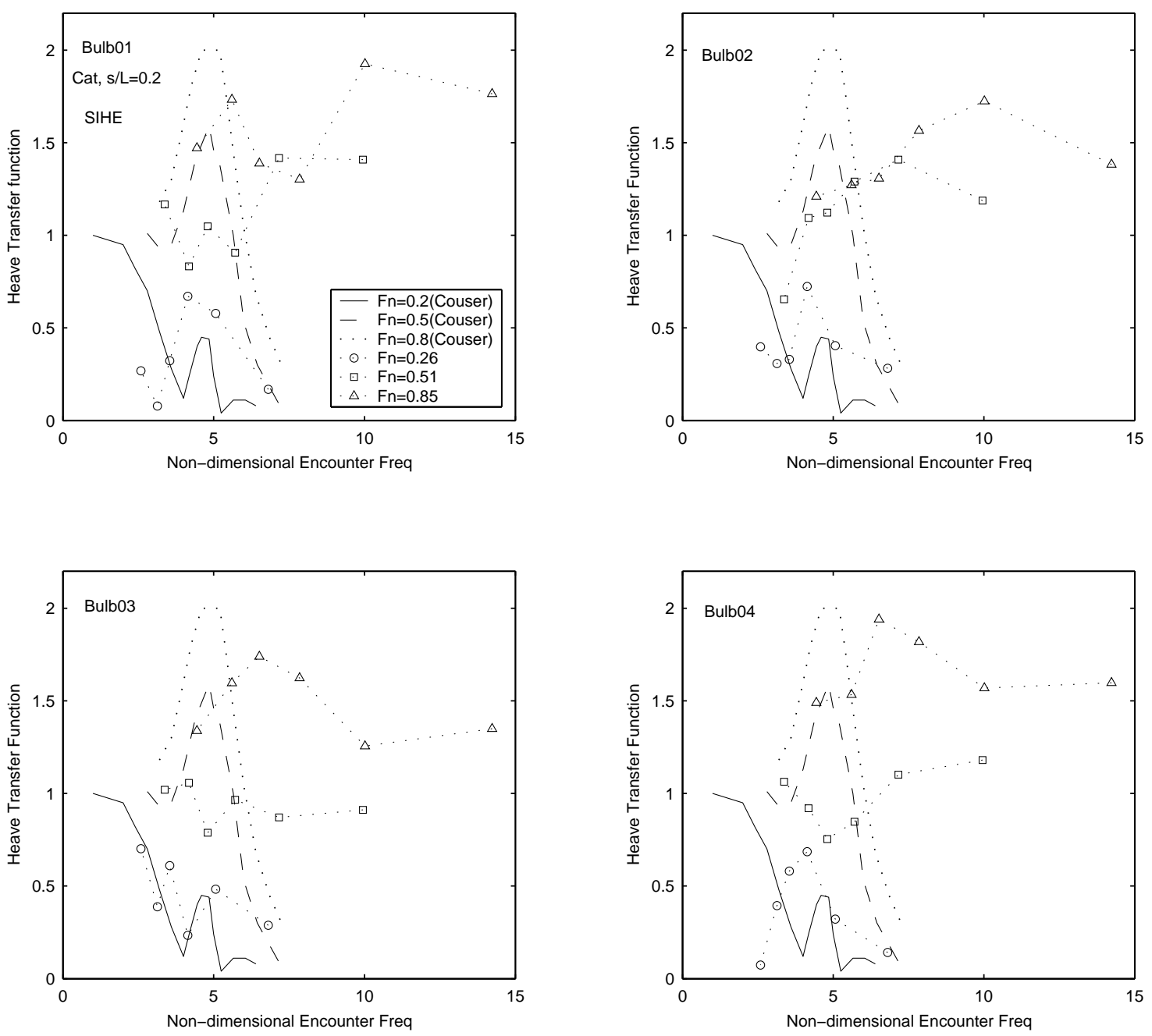

Figure 10. Response Functions of Heave for Model NPL5b Catamaran $s / L=0.2$ with and without bulbous bow 

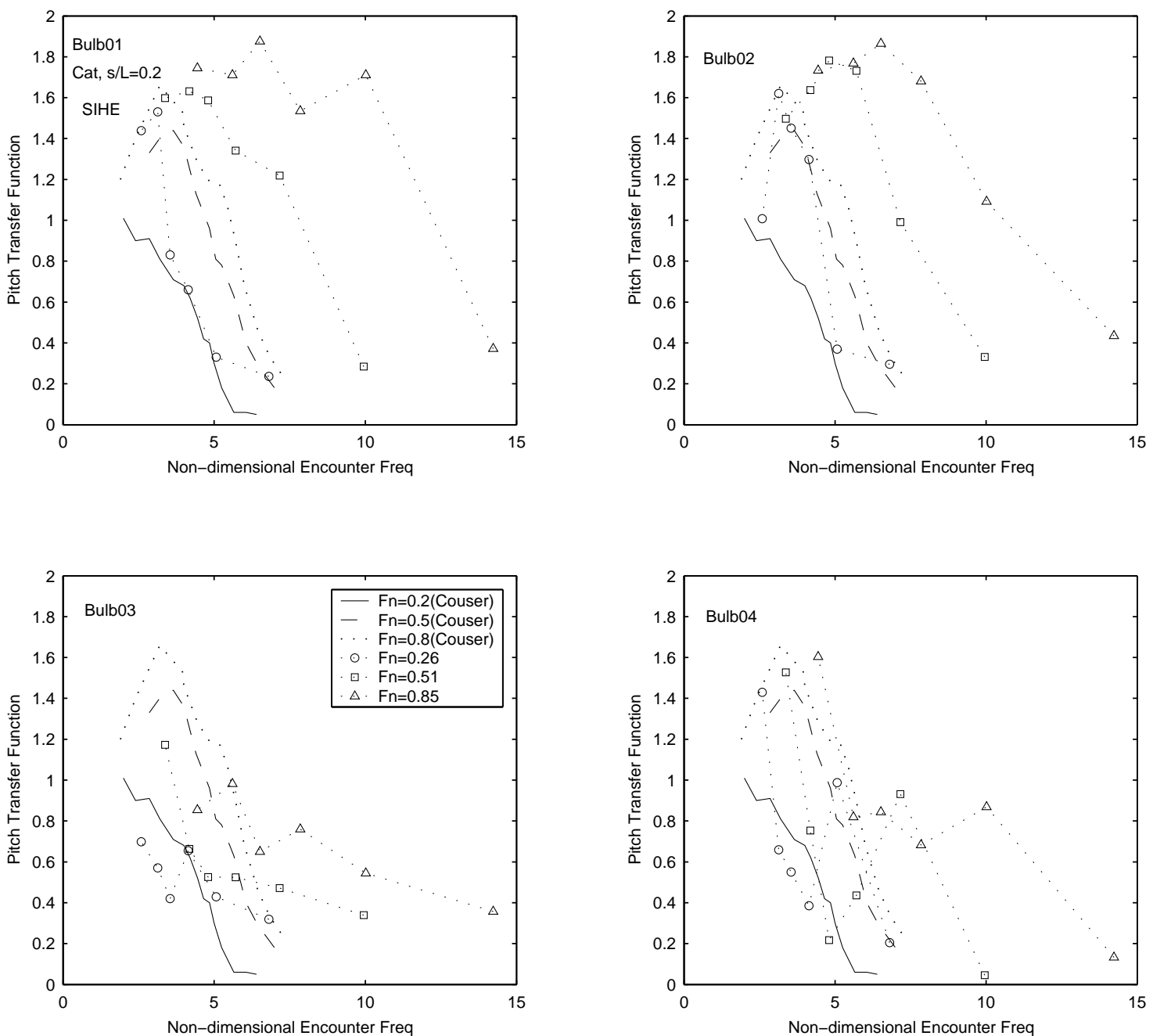

Figure 11. Response Functions of Pitch for Model NPL5b Catamaran $s / L=0.2$ with and without bulbous bow 


$$
\sigma_{A W}=\frac{R_{A W}}{\rho g\left(\zeta_{a}\right)^{2}\left(B^{2} / L\right)}
$$

where

$R_{A W}$ added resistance in waves, $N$

$\rho$ density of water, $\mathrm{kg} / \mathrm{m}^{3}$

$g$ gravity acceleration, $\mathrm{m} / \mathrm{s}^{2}$

$B$ breadth, $m$

$L$ length, $m$

$\zeta_{a}$ wave amplitude, $m$

The added resistance in waves is due mainly to non-viscous effects; thus added resistance experiments can be carried out with small models, since no scale effect has to be considered, Bhattacharyya (1978) [17]. Added resistance coefficient for the original model NPL5b catamaran $s / L=0.2$ without bulbous bow is shown in Figure 14 which is reproduced from Couser (1996) [16].

The measured added resistance is not very small as illustrated by the results in Figures 12 to 16 . Figures 12 and 13 show dimensionless added resistance as function of non-dimensional encounter frequency for catamaran $s / L=0.2$ model fitted with bulb01, bulb02, bulb03 and bulb04. These figures show that the added resistance in waves varies with speed.

For model fitted with bulb01, bulb03 and bulb04, the added resistance is found to rise notably when the wavelength decreases especially in the low speed region as illustrated in Figures 12 to 16.

But, the same tendency is not that clear for model fitted with bulb02 as shown in the above figures. It was found that the catamaran fitted with bulb02 produced less resistance in waves in some places compared to the respective calm water resistance. This is not a plausible result, but the reasons at present are not fully understood or explainable.

Figure 17 shows a comparison of added resistance coefficient by catamaran $s / L=$ 0.2 with and without bulbous bow. The added resistance coefficients for model without bulbous bow are represented by lines(solid, dashed, dotted) whereas for the model with bulbous bow are represented by a combination of dotted lines and symbols (circle, square, triangle). These figures clearly show that the catamarans fitted with bulbous bows produce smaller added resistance coefficient compared to the original hull form without a bulbous bow.

In spite of the large scatter of the added resistance coefficient at various Froude numbers, the bulb02 offers the lowest value in all condition as shown in Figure 17. This also could be seen in 3D plot as shown in Figures 15 and 16. These 3D plot have been produced by using MATLAB software and its interpolation and smoothing functions.

\subsubsection{Pitch and Heave Measurement}

For description of ship motion in the vertical plane in waves, the response functions of heave and pitch are sufficient as found out by Blume and Kracht (1985) [18]. Pitch and heave were monitored for all the tests. 
The dimensionless motion amplitudes are defined by:

Heave:

$$
Z_{a}^{\prime}=Z_{a} / \zeta_{a}
$$

Pitch:

$$
\theta_{a}^{\prime}=\theta_{a} \cdot L / 2 \pi \zeta_{a}
$$

The experimental frequency response functions of heave and pitch are plotted in Figures 4 and 5. An alternative presentation of the same results is given in Figures 6 and 7. Those figures show the results measured for all variants of the model and compared at the same Froude numbers.

In Figures 6 and 7 it can be seen that the maximum amplitudes occur for wavelengths between $0.75 \mathrm{~L}$ to $1.5 \mathrm{~L}$. As illustrated by the figures, a bulbous bow has no significant effect on heave and pitch up to $\lambda / L=0.5$, since there is no significant variation in the maximum amplitudes of heave and pitch produced by bulb01, bulb02, bulb03 and bulb04 below this wavelength.

From Figure 5 it shows that an increasing bulb size (i.e bulb03 and bulb04) is accompanied by a reduction of pitch amplitudes in most cases at higher wavelengths, i.e $\lambda / L>1.0$ for $F_{n}=0.26, \lambda / L>0.75$ for $F_{n}=0.51,0.71$ and $\lambda / L>0.5$ for $F_{n}=0.85$. This observation could be connected to the damping coefficients as mentioned by Kracht(1978)[11]. In detail, the bulbous bow mitigates the pitching motion of the ship by its higher damping.

Figures 4 and 6 showing heave transfer functions, in some cases it shows that the wavelength and Froude number have a much greater effect than bulbous bow size. A fundamental conclusion in these studies, for wave lengths shorter than $0.5 \mathrm{~L}$, there very little model response at any speed as mentioned before.

Figures 8 and 9 show the the heave and pitch transfer function in head seas condition for original hull NPL5b catamaran $s / L=0.2$ at $F_{n}=0.2,0.5$ and 0.8 respectively. These figures are reproduced from the thesis of Taunton (2001) [19].

The results also have been compared with model fitted with four different bulbous bows as shown in Figures 10 and 11.

\section{Discussion}

The work described in this paper covers the experimental determination of the seakeeping properties of catamaran $s / L=0.2$ fitted with four different bulbous bows. Measurements of heave, pitch and wash as well as added resistance due to waves have been made. When the ship model is fitted with bulb01 which is the shortest bulbous bow, the added resistance is found to rise dramatically when the wavelength decreases, and the same thing shown by the model fitted with bulb03 and bulb04. Whereas for model with bulb02, this trend is not very clear but generally it offers the lowest value of added resistance. Based on this, it is concluded that the vessel having least resistance in calm water does not necessarily show the lowest added resistance in seaway or rough water. In addition, it was found that the magnitude of added resistance increases as $F_{n}$ increases. 
Pitch motion influenced by the size of the bulbous bow i.e. pitch amplitude decreases as bulbous bow size increases as shown in Figure 11. But the effect of bulbous size on heave motion is less pronounced as shown in Figure 10. However, in heave motion the wavelength and Froude number have a much greater effect than the size of bulbous bow.

Tables 7 to 9 show the ranking of the bulbous bows based on the experimental results of model testing in regular waves. These ranking were developed on three criteria namely added resistance in waves, heave and pitch amplitudes. They are arranged from best to worst with best being that bulb which had the lowest added resistance, heave and pitch over the $F_{n}=0.26,0.51,0.71$ and 0.85 .

\begin{tabular}{|c||cccc|}
\hline \multicolumn{1}{|c|}{$\begin{array}{c}\text { Fn=0.26 } \\
\text { Rank }\end{array}$} & \multicolumn{4}{c|}{ Lambda/L } \\
\hline \hline 1 & bulb04 & bulb03 & bulb01 & bulb04 \\
2 & bulb01 & bulb02 & bulb02 & bulb01 \\
3 & bulb03/02 & bulb04 & bulb03/04 & bulb02 \\
4 & na & bulb01 & na & bulb03 \\
\hline \hline
\end{tabular}

\begin{tabular}{|c||cccc|}
\hline \multirow{2}{*}{$\begin{array}{c}\text { Fn=0.51 } \\
\text { Rank }\end{array}$} & \multicolumn{4}{c|}{ Lambda/L } \\
\hline \hline 1 & bulb03 & bulb04 & bulb01 & bulb02 \\
2 & bulb02/04 & bulb01 & bulb04 & bulb03 \\
3 & bulb01 & bulb03 & bulb03 & bulb04 \\
4 & na & bulb02 & bulb02 & bulb01 \\
\hline \hline
\end{tabular}

\begin{tabular}{|c|cccc|}
\hline \multirow{2}{*}{\begin{tabular}{c|c} 
Fn=0.71 \\
Rank
\end{tabular}} & \multicolumn{4}{|c|}{ Lambda/L } \\
\hline \hline 1 & bulb03 & bulb03 & bulb02 & bulb02 \\
\hline 2 & bulb02 & bulb04 & bulb04 & bulb03 \\
3 & bulb04 & bulb01 & bulb01 & bulb04 \\
4 & bulb01 & bulb02 & bulb03 & bulb01 \\
\hline
\end{tabular}

\begin{tabular}{|c||cccc|}
\hline \multirow{2}{*}{\begin{tabular}{c|c} 
Fn=0.85 \\
Rank
\end{tabular}} & \multicolumn{4}{|c|}{ Lambda/L } \\
\hline 1 & bulb03 & bulb01 & bulb02 & bulb02 \\
2 & bulb02 & bulb02 & bulb04 & bulb03 \\
3 & bulb04 & bulb03 & bulb03 & bulb01/04 \\
4 & bulb01 & bulb04 & bulb01 & na \\
\hline \hline
\end{tabular}

Table 7. Catamaran s/L=0.2: Relative Ranking of Bulbous Bows based on Heave Amplitude

\begin{tabular}{|c||cccc|}
\hline \multirow{2}{*|}{$\begin{array}{c}\text { Fn=0.26 } \\
\text { Rank }\end{array}$} & \multicolumn{4}{|c|}{ Lambda/L } \\
\hline \hline 1 & bulb04 & bulb04 & bulb03 & bulb03 \\
2 & bulb01 & bulb01/03 & bulb04 & bulb02 \\
3 & bulb02 & bulb02 & bulb01 & bulb01/04 \\
4 & bulb03 & na & bulb02 & na \\
\hline
\end{tabular}

\begin{tabular}{|c||cccc|}
\hline \multirow{2}{*||}{$\begin{array}{c}\text { Fn=0.51 } \\
\text { Rank }\end{array}$} & \multicolumn{4}{c|}{ Lambda/L } \\
\hline \hline 1 & bulb04 & bulb04 & bulb03 & bulb03 \\
2 & bulb01 & bulb03 & bulb04 & bulb02/04 \\
3 & bulb02/03 & bulb01 & bulb01/02 & bulb01 \\
4 & na & bulb02 & na & na \\
\hline
\end{tabular}

\begin{tabular}{|c||cccc|}
\hline \multirow{2}{*|}{$\begin{array}{c}\text { Fn=0.71 } \\
\text { Rank }\end{array}$} & \multicolumn{4}{c|}{ Lambda/L } \\
\hline 1 & bulb04 & bulb04 & bulb04 & bulb03 \\
2 & bulb01 & bulb03 & bulb03 & bulb04 \\
3 & bulb03 & bulb01 & bulb01 & bulb02 \\
4 & bulb02 & bulb02 & bulb02 & bulb01 \\
\hline \hline
\end{tabular}

\begin{tabular}{|c||cccc|}
\hline \multirow{2}{*}{$\begin{array}{c}\text { Fn=0.85 } \\
\text { Rank }\end{array}$} & \multicolumn{4}{|c|}{ Lambda/L } \\
\hline 1 & 0.5 & 1 & 1.5 & 2 \\
\hline 2 & bulb04 & bulb04 & bulb04 & bulb03 \\
3 & bulb03/01 & bulb03 & bulb03 & bulb04 \\
4 & bulb02 & bulb01 & bulb01 & bulb01/02 \\
na & bulb02 & bulb02 & na \\
\hline
\end{tabular}

Table 8. Catamaran $\mathrm{s} / \mathrm{L}=0.2$ : Relative Ranking of Bulbous Bows based on Pitch Amplitude 


\begin{tabular}{|c||cccc|}
\hline \multirow{2}{*}{$\begin{array}{c}\text { Fn=0.26 } \\
\text { Rank }\end{array}$} & \multicolumn{4}{|c|}{ Lambda/L } \\
\hline \hline 1 & bulb02 & bulb02 & bulb02 & bulb02 \\
2 & bulb04 & bulb01/04 & bulb04 & bulb04 \\
3 & bulb01 & bulb03 & bulb01 & bulb01 \\
4 & bulb03 & na & bulb03 & bulb03 \\
\hline
\end{tabular}

\begin{tabular}{|c||cccc|}
\hline \multirow{2}{*|}{$\begin{array}{c}\text { Fn=0.51 } \\
\text { Rank }\end{array}$} & \multicolumn{4}{|c|}{ Lambda/L } \\
\hline \hline 1 & 0.5 & 1 & 1.5 & 2 \\
\hline 2 & bulb01/02 & bulb02 & bulb02 & bulb02 \\
3 & bulb04 & bulb04 & bulb04 & bulb04 \\
4 & bulb03 & bulb01 & bulb01 & bulb01 \\
na & bulb03 & bulb03 & bulb03 \\
\hline
\end{tabular}

\begin{tabular}{|c||cccc|}
\hline \multirow{2}{*}{$\begin{array}{c}\text { Fn=0.71 } \\
\text { Rank }\end{array}$} & \multicolumn{4}{|c|}{ Lambda/L } \\
\hline \hline 1 & bulb02 & bulb02 & bulb02 & bulb02 \\
2 & bulb01 & bulb04 & bulb04 & bulb01 \\
3 & bulb04 & bulb01 & bulb03 & bulb04 \\
4 & bulb03 & bulb03 & bulb01 & bulb03 \\
\hline
\end{tabular}

\begin{tabular}{|c||cccc|}
\hline \multirow{2}{*||}{$\begin{array}{c}\text { Fn=0.85 } \\
\text { Rank }\end{array}$} & \multicolumn{4}{|c|}{ Lambda/L } \\
\hline 1 & 0.5 & 1 & 1.5 & 2 \\
\hline 2 & bulb02 & bulb02 & bulb02 & bulb02 \\
3 & bulb01 & bulb01 & bulb04 & bulb01/04 \\
4 & bulb03/04 & bulb04 & bulb03 & bulb03 \\
na & bulb03 & bulb01 & na \\
\hline
\end{tabular}

Table 9. Catamaran $\mathrm{s} / \mathrm{L}=0.2$ : Relative Ranking of Bulbous Bows based on Added Resistance

Table 10 shows a cumulative relative ranking of the bulbous bows which is produced from Tables 7, 8 and 9. It is also interesting that the maximum added resistance is not accompanied by maximum amplitude of motion. It is believed to be caused by the phase relations between motions and waves which is also play a part in added resistance.

It can be noted that bulb02 is good for resistance whilst bulb03 and bulb04 are good for heave and pitch motions respectively. The weighting of the bulbous bows between the criteria(resistance, heave and pitch) and an ultimate choice will depend on likely weather conditions for a particular route.

\begin{tabular}{|l|c|c|c|}
\hline Rank & Added Resistance & Heave & Pitch \\
\hline \hline 1 & bulb02 & bulb03 & bulb04 \\
2 & bulb04 & bulb02 & bulb03 \\
3 & bulb01 & bulb04 & bulb01 \\
4 & bulb03 & bulb01 & bulb02 \\
\hline
\end{tabular}

Table 10. Catamaran $s / L=0.2$ :Relative Ranking of Bulbous Bows in Regular Waves

\section{Deep Water Tests}

The results presented in this paper clearly show that the high-speed displacement vessel fitted with bulbous bows has some promising characteristics in wash, resistance and seakeeping.

It should be underlined that, all results mentioned in this paper are based on the investigation on one of the NPL series of high speed displacement hull form namely Model $5 \mathrm{~b}$. This model has been tested in monohull and catamaran configurations. In order to investigate the effect of bulbous bow on wash and others ship performance criteria such 
as resistance and seakeeping, this model underwent slight modification from station 8 up to stem to enable to accommodate the bulbous bow.

From this study, it seems that the bulbous bow has an important effect on the resistance and wash. For catamaran $s / L=0.2$, it was found that the bulbous bows reduce the residuary resistance coefficient by at least $30 \%$. Hence, bulb03 and bulb04 are preferable since they reduce the maximum residuary resistance coefficient by $40 \%$ and $38 \%$ respectively. The residuary resistance coefficient of the catamaran configurations $(s / L=0.2,0.3,0.4)$ was found tend to a constant value at $F_{n}>0.7$, irrespective of the demihull spacing. At moderate Froude numbers i.e. $0.4<F_{n}<0.7$ the residuary resistance was found to increase deliberately with reducing $s / L$ i.e. a smaller separation leads to higher interference.

An important observation can be made about the effects of the bulbous bow geometry on performance. In general, the resistance advantages derived from adding a bulbous bow to the NPL5b hull seemed to increase with increasing bulb volume. Bulb04, (the longest bulb) illustrated this point by having the lowest specific resistance over the considered speed range for monohull configuration and vice-versa for catamaran, $s / L=0.2$ i.e. bulb01 and bulb02 offer the lowest specific resistance. This is probably due to the effect of wave interference as a result of two demihulls running side by side.

The bulbs efficiency plot for catamaran $s / L=0.2$, shows that bulb01 and bulb02 are the most efficient compared to bulb03 and bulb04.

The experimental results revealed the tested bulbous bows have positive effect on resistance for all sizes and Froude numbers at full load condition.

In catamaran configurations $s / L=0.2,0.3,0.4$, the wash height decreases with increasing hull separation. For separation ratio, $s / L=0.2$, bulb04 gives the lowest wash height followed closely by bulb03, bulb02 and bulb01 accordingly. The changes of nondimensional maximum wash height with $F_{n}$ appear to produce a similar trend to those of wave-making resistance coefficients as expected.

In monohull configuration, bulb02 produces the lowest wash and almost coincides with the wash produced by bulb04. However, the non-dimensional wash heights produced by bulb01 and bulb03 are approximately four and six times higher than those generated by bulb02 and bulb04 respectively.

The deep water results also found that the running trim varies with speed and bulb size i.e. bulb01 and bulb04 gave the lowest and the highest trim respectively.

\section{General Remarks \& Conclusions}

It is important to note that the bulbous bows with circular cross section offer a significant reduction in wave making resistance coefficients as well as reductions in wash height, together with the practical advantage of a simple construction procedure.

It would be useful for ship designers to have a tool that could predict the wavemaking properties of a hull to such an extent that the wash of the vessel could be minimised. As all design is a compromise business in nature, a designer must trade-off the conflicting requirements of minimum wash for minimum resistance and excellent seakeeping. 


\begin{tabular}{|l||c|c|c|c|c|c|}
\hline Bulb No. & $C_{L P R}$ & $C_{B B}$ & $C_{Z B}$ & $C_{A B L}$ & $C_{A B T}$ & $C_{\nabla P R}$ \\
\hline \hline 0 & 0.011 & 0.194 & 0.293 & 0.064 & 0.125 & 0.0014 \\
\hline 1 & 0.034 & 0.165 & 0.46 & 0.174 & 0.086 & 0.0028 \\
\hline 2 & 0.030 & 0.165 & 0.46 & 0.165 & 0.088 & 0.0030 \\
\hline 3 & 0.040 & 0.165 & 0.46 & 0.219 & 0.088 & 0.0039 \\
\hline 4 & 0.034 & 0.200 & 0.46 & 0.174 & 0.106 & 0.0035 \\
\hline 5 & 0.030 & 0.200 & 0.46 & 0.165 & 0.106 & 0.0036 \\
\hline 6 & 0.040 & 0.200 & 0.46 & 0.219 & 0.106 & 0.0047 \\
\hline 7 & 0.020 & 0.165 & 0.46 & 0.110 & 0.088 & 0.0020 \\
\hline 8 & 0.010 & 0.165 & 0.46 & 0.056 & 0.088 & 0.0010 \\
\hline
\end{tabular}

Table 11. Kracht bulb parameters

\section{References}

[1] Abdul Ghani, M. P. and Wilson, P. A. . Experimental analysis of catamaran forms with bulbous bows operating in shallow water. International Shipbuilding Progress, 56:29-57, 2009.

[2] Kofoed-Hansen, H, Jensen, T, Kirkegaard, J and Fuchs, J. Prediction of Wake Wash from High-Speed Craft in Coastal Areas. In International Conference Hydrodynamics of High Speed Craft, London, November 1999.

[3] Keuning, J. and Pinkster, J. The effect of bow shape on the seakeeping performance of a fast monohull. In The 6th International Conference on Fast Sea Transportation, FAST2001, Southampton, Sept 2001.

[4] Doctors, L. J., Phillips, S.J, and Day, A. Focussing the wave-wake system of a high-speed ferry. In The 6th International Conference on Fast Sea Transportation, FAST2001, Southampton, Sept 2001.

[5] Broadbent, C., and Kennell, C. Monohull, Catarmaran, Trimaran and SES high speed sealift vessels. In The 6th International Conference on Fast Sea Transportation, FAST2001, Southampton, Sept 2001.

[6] Molland, A.F., Wilson, P. A., Taunton, D. J. Chandraprabha, S. and Abdul Ghani, M. P. Resistance and wash measurements on a series of high speed displacement monohull and catamaran forms in shallow water. International Journal of Maritime Engineering, 146(2):19-38, 2004.

[7] Doyle, R., Whittaker, T. J. T. and Elsa $\beta$ er, B. A Study of Fast Ferry Wash in Shallow Water. In The 6th International Conference on Fast Sea Transportation, FAST2001, Southampton, Sept 2001.

[8] Insel, M and Molland A.F. An Investigation into the Resistance Components of High Speed Displacement Catamaran. Transactions of the Royal Institution of Naval Architects, 134, 1992.

[9] Schneekluth, H. Ship Design for Efficiency and Economy. Butterworths, London, UK., 1987.

[10] Wigley, W.C.S. The Theory of Bulbous Bow and its Practical Application. Transactions of NECIES, 52:65-88, 1936.

[11] Kracht, A.M. Design of Bulbous bow. Transactions of The Society of Naval Architects and Marine Engineers, 86, 1978.

[12] Wehausen, J.V. The Wave Resistance of Ships. Advances in Applied Mechanics, 13:93-245, 1973.

[13] Roddan, G. Bulbous bows for Trawler Yachts and the Long Range Cruiser. In Fifth Annual West Marine Trawler Fest, Poulsbo, Washington, USA, November 1999

[14] Hoffman, M. On Optimal Dimensions of Fast Vessel for Shallow Water. In Proc. of the 7th International Symposium on Practical Design of Ships and Mobile Units, PRAD'98, The Hague, Sept 1998.

[15] Abdul Ghani, M. P. Design aspects of catamarns operating at high speed in shallow water. $\mathrm{PhD}$ thesis, University of Southampton, 2003.

[16] Couser, P.R. An Investigation into the Performance of High-speed Catamarans in Calm water and Waves. PhD thesis, University of Southampton, UK, 1996.

[17] Bhattacharyya, R. Dynamics of Marine Vehicles. A Wiley-Interscience Publication, USA, 1978.

[18] Blume, P and Kracht, A.M. Prediction of the Behavior and Propulsive Performance of Ships with Bulbous Bow in Waves. Transactions of The Society of Naval Architects and Marine Engineers, 93:7994, 1985. 


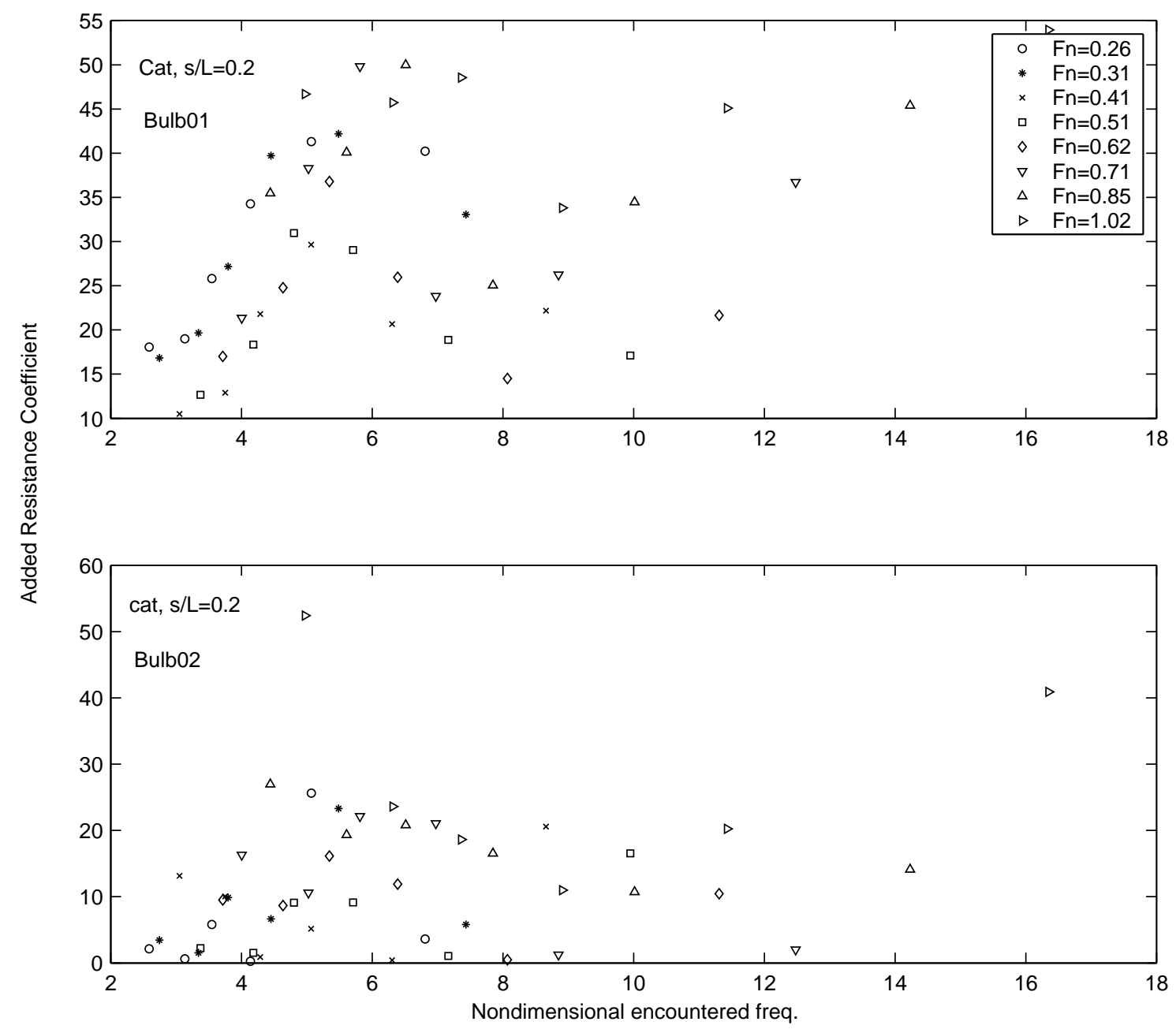

Figure 12. Catamaran $s / L=0.2$ with Bulb01 and Bulb02: Added Resistance Coefficient versus Non-dimensional Frequency of Encounter 


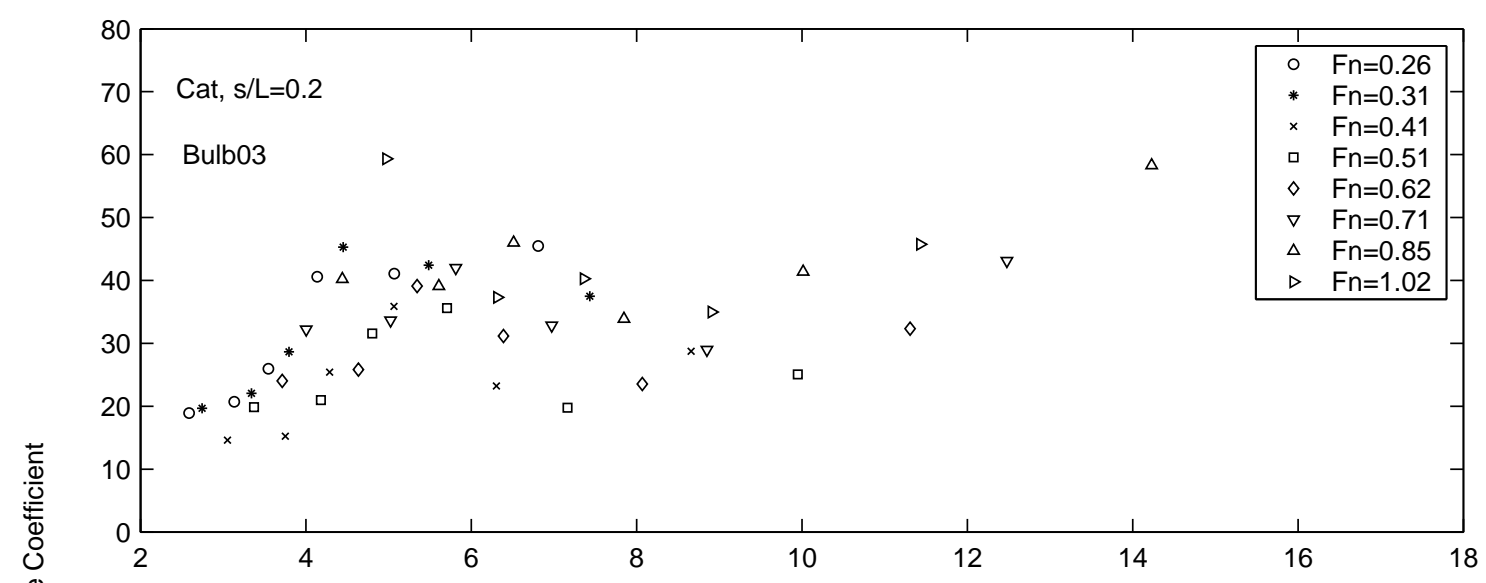

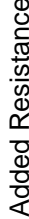

은

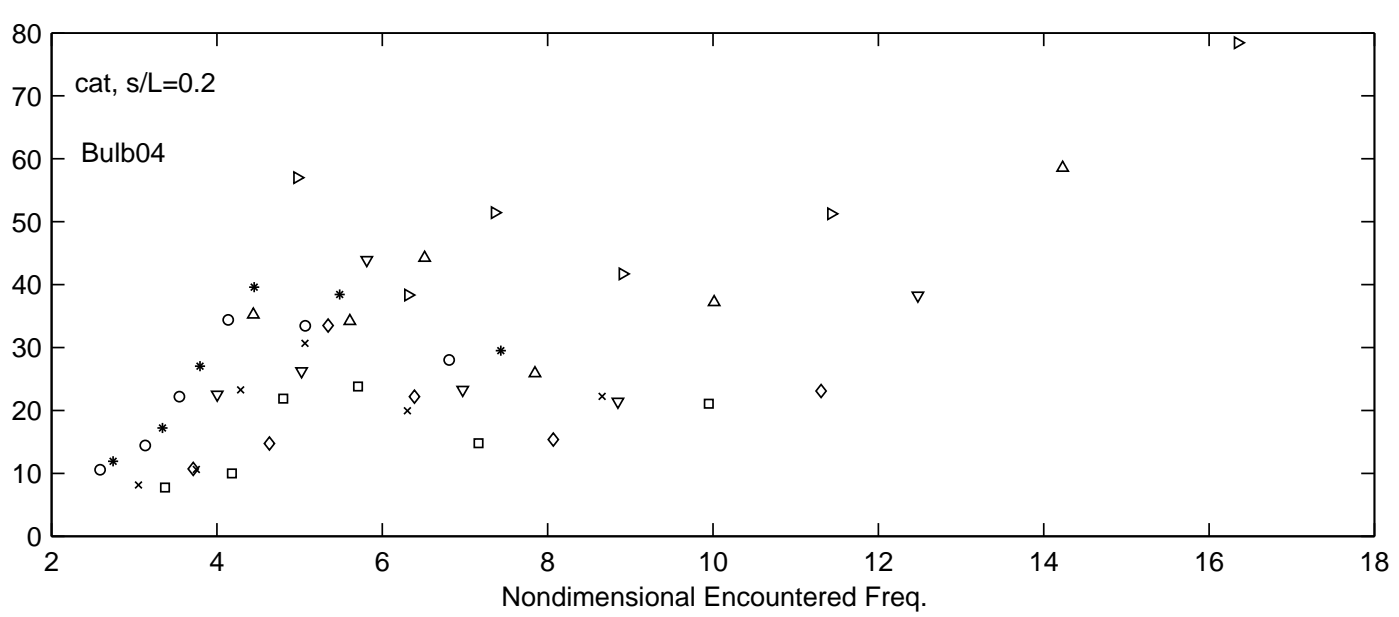

Figure 13. Catamaran $\mathrm{s} / \mathrm{L}=0.2$ with Bulb03 and Bulb04: Added Resistance Coefficient versus Non-dimensional Frequency of Encounter 


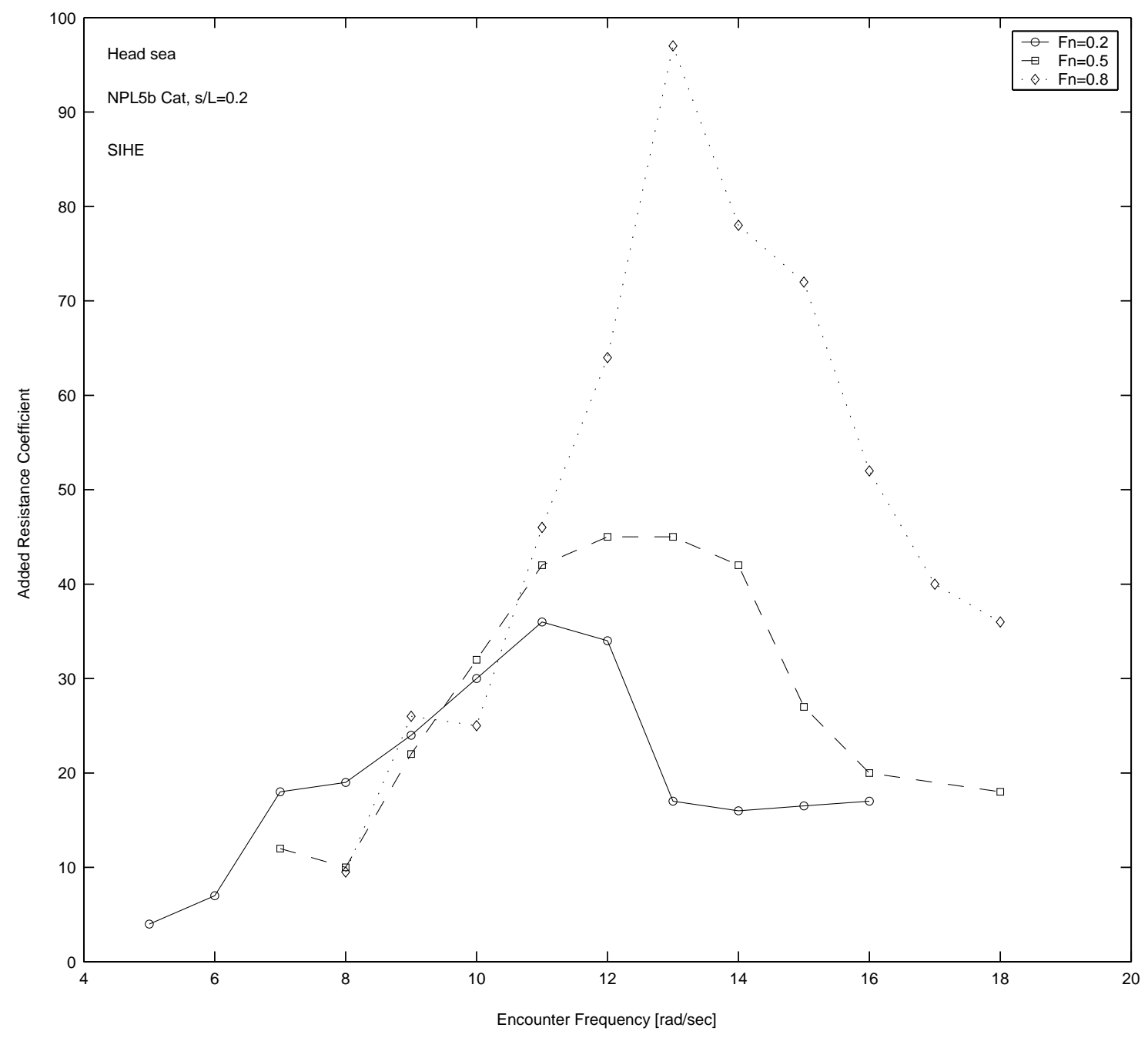

Figure 14. Catamaran $s / L=0.2$ without bulbous bow: Added Resistance Coefficient versus Encounter Frequency[16] 

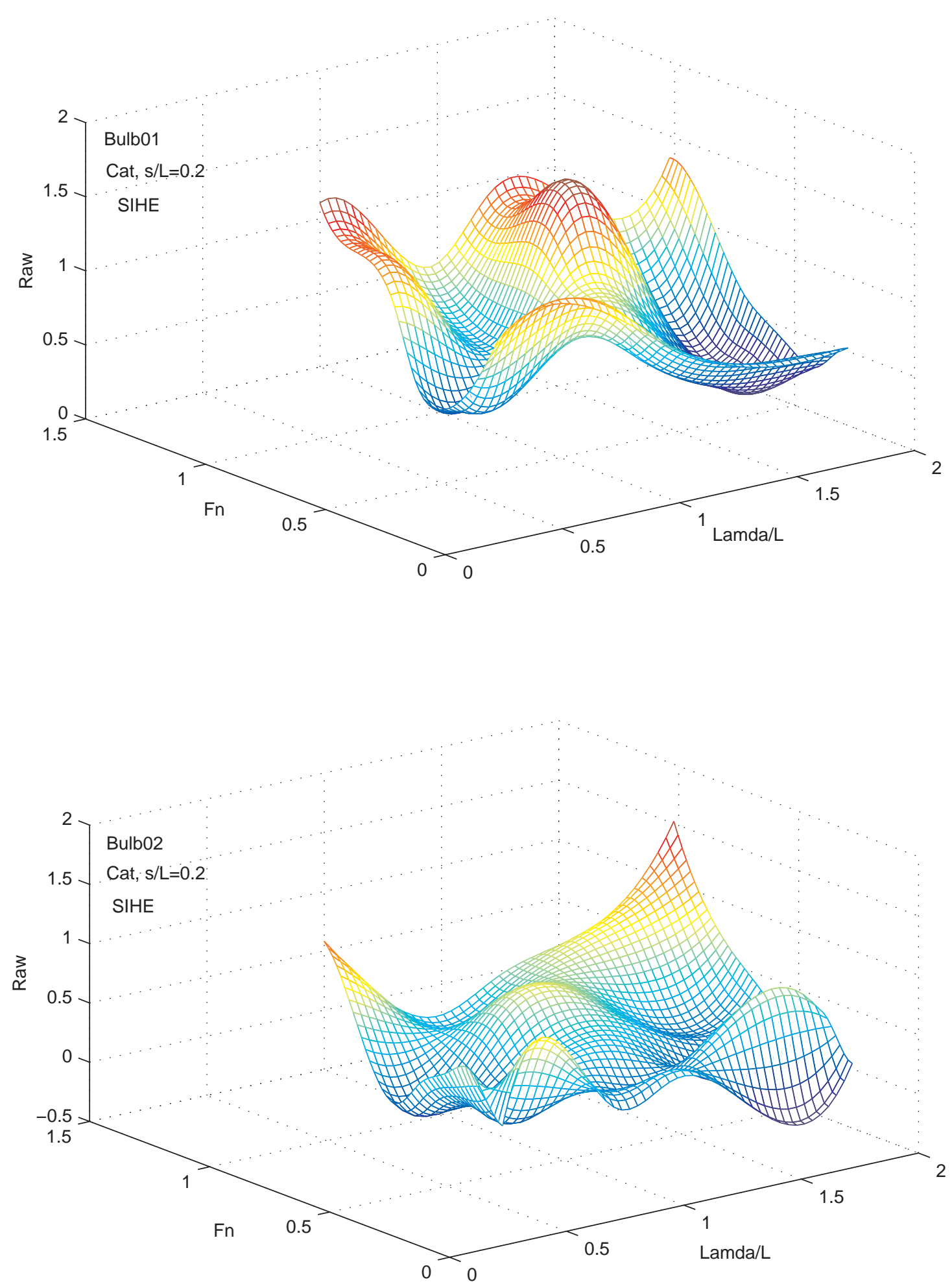

Figure 15. Catamaran $\mathrm{s} / \mathrm{L}=0.2$ with Bulb01 and Bulb02: Added Resistance in Waves 

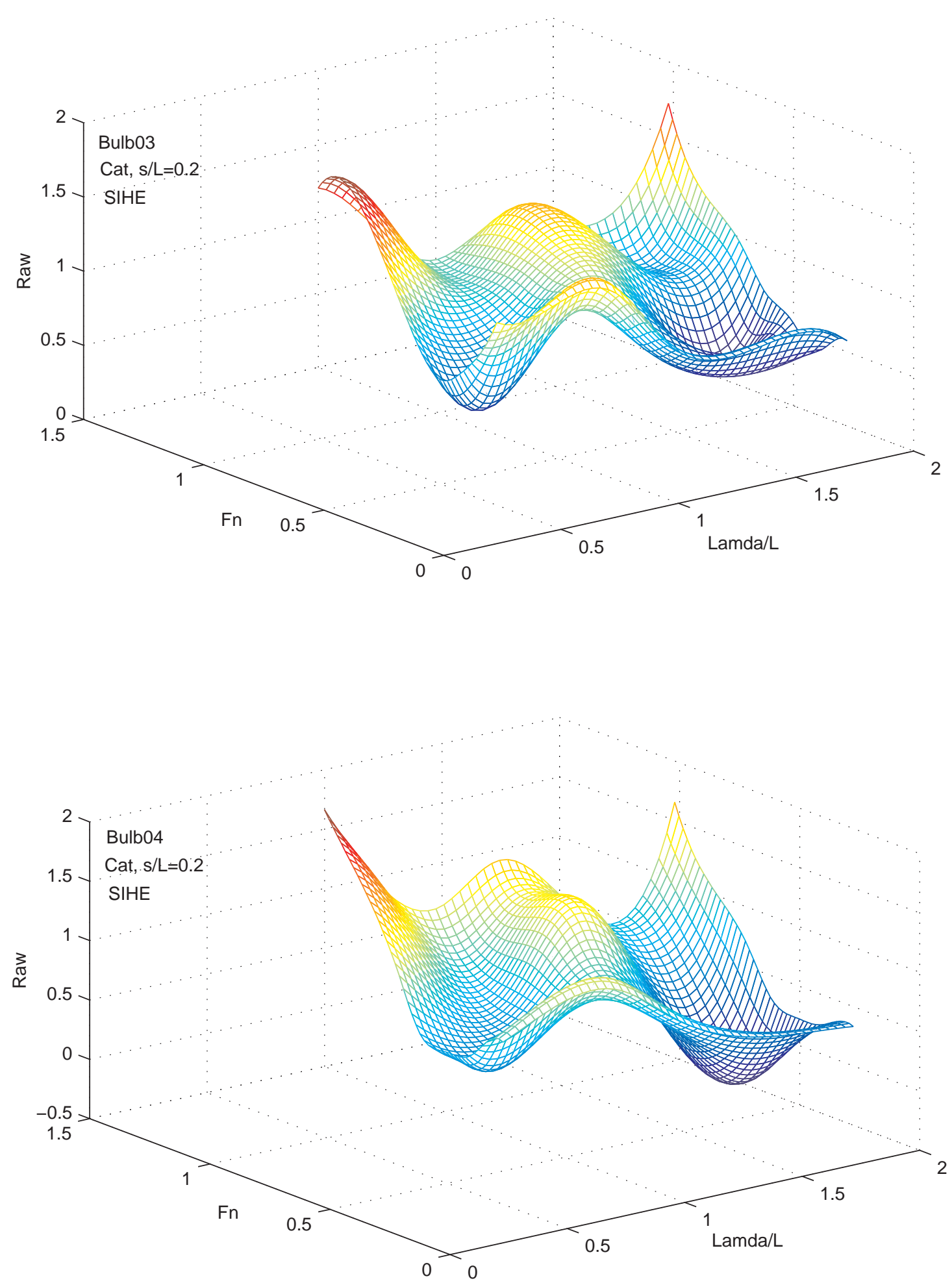

Figure 16. Catamaran $\mathrm{s} / \mathrm{L}=0.2$ with Bulb03 and Bulb04: Added Resistance in Waves 

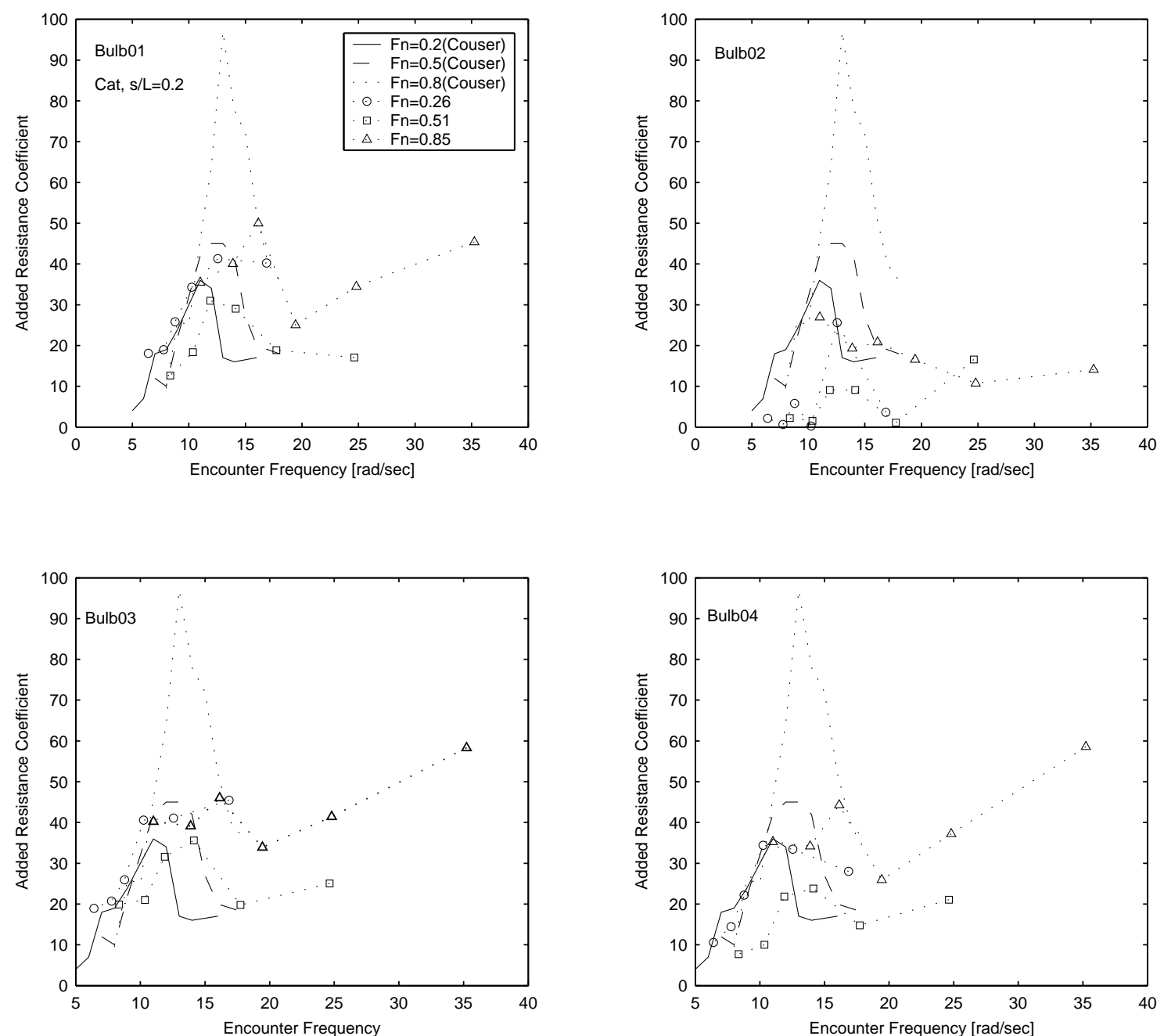

Figure 17. Catamaran $\mathrm{s} / \mathrm{L}=0.2$ with and without bulbous bow: Added Resistance Coefficient versus Encounter Frequency 
[19] Taunton, D.J. Methods for assessing the Seakeeping Performance of High-Speed Displacement Monohulls and Catamarans. PhD thesis, University of Southampton, UK, 2001.

[20] Abdul Ghani, M.P and Wilson, P.A. Wake Wash From High Speed Displacement Craft. In Asia Pacific Maritime Congress - 90th Anniversary KSNAJ, Kobe, Japan, May 21 - 232002. 99(2):245-256, 1973.

[21] Tuck, E.O. Ship-Hydrodynamic Free-Surface Problems Without Waves. Journal of Ship Research, 35(4):277-287, Dec 1991. 